\title{
AS CAPACIDADES DE INOVAÇÃO EM STARTUPS: CONTRIBUIÇÕES PARA UMA TRAJETÓRIA DE CRESCIMENTO
}

INNOVATION CAPABILITIES IN STARTUPS: CONTRIBUTIONS TOWARDS GROWTH

LAS CAPACIDADES DE INNOVACIÓN EN STARTUPS: CONTRIBUCIONES PARA UNA TRAYECTORIA DE CRECIMIENTO

\author{
ANDRÉIA CRISTINA DULLIUS \\ Mestranda \\ Universidade Federal do Rio Grande do Sul - Brasil \\ andreia.dullius@ufrgs.br \\ PAOLA RÜCKER SCHAEFFER \\ Doutoranda \\ Universidade Estadual de Campinas - Brasil \\ paolaschaeffer@ige.unicamp.br \\ Submetido em: 17/10/2015 \\ Aprovado em: 31/03/2016 \\ Doi:alcance.v.23n.1.p34-50
}

\section{RESUMO}

0 artigo visa analisar as capacidades de inovação predominantes em startups, com base no modelo de capacidades de Zawislak et al. (2013), o qual compreende as capacidades de desenvolvimento, de operação, de gestão e de transação. Para tanto, realizou-se um estudo do tipo exploratório com seis empresas: quatro startups e duas firmas, sendo que essas iniciaram as suas respectivas trajetórias como startups. Os resultados revelam, primeiramente, que as startups possuem apenas as capacidades de desenvolvimento e de transação, enquanto as firmas possuem as quatro capacidades desenvolvidas. As capacidades de operação e de gestão, além de serem inexistentes ou incipientes nas startups, passam a integrar as suas rotinas apenas na medida em que elas se consolidam e crescem como organização. Além disso, destaca-se também que a rede de relacionamentos das startups é um dos fatores de maior importância nos primeiros anos da startup, tendo em vista a necessidade de obter acesso a investidores e potenciais clientes.

Palavras-chave: Startup. Capacidades de Inovação. Brasil.

\begin{abstract}
This paper analyzes the predominant innovation capabilities of startup companies, based on the innovation capabilities model of Zawislak et al. (2013), which analyzes development, operation, management and transaction capabilities. This exploratory study was conducted with six companies: four startups and two established firms that also had also begun as startups. The results show, firstly, that the startups have development and transactional capabilities, while firms have all four capabilities developed. The operational and management capabilities, initially nonexistent or underdeveloped, become part of the routines of the startups once the company is established and grows as an organization. It is also highlighted that the network of relationships is one of the most important factors in the early years of the startup, as it needs to gain access to investors and potential customers.
\end{abstract}

Keywords: Startup. Innovation capabilities. Brazil. 


\section{RESUMEN}

Este artículo tiene el propósito de analizar las capacidades de innovación predominantes en startups con base en el modelo de capacidades de Zawislak et al. (2013), que comprende las capacidades de desarrollo, de operación, de gestión y de transacción. Para ello se realizó un estudio de tipo exploratorio con seis empresas, cuatro startups y dos firmas que habían iniciado sus respectivas trayectorias como startups. Los resultados revelan, en primer lugar, que las startups poseen apenas las capacidades de desarrollo y de transacción, mientras que las firmas han desarrollado las cuatro capacidades. Las capacidades de operación y de gestión, además de ser inexistentes o incipientes en las startups, pasan a integrar sus rutinas solo en la medida en que se consolidan y crecen como organización. Además, se destaca también que la red de relaciones de las startups es uno de los factores de mayor importancia en los primeros años de la startup, considerando la necesidad de obtener acceso a inversionistas y potenciales clientes.

Palabras clave: Startup. Capacidades de Innovación. Brasil.

\section{INTRODUÇÃO}

A hipótese schumpeteriana pressupõe que grandes firmas contribuem com uma parcela desproporcionalmente maior na geração de avanços tecnológicos (SCHUMPETER, 1985). Entre os argumentos de suporte às vantagens da grande firma estão 0 da disponibilidade de maiores recursos internos, a existência de vantagens de escala no processo de pesquisa e desenvolvimento (P\&D), a maior diluição dos custos fixos da inovação e a maior complementariedade entre o processo de P\&D e os demais. Contudo estudos subsequentes, que questionaram essa hipótese, evidenciaram que a relação entre o tamanho da firma e a intensidade de investimentos em P\&D não pode ser estabelecida, sendo atribuído ao tipo de indústria a maior parte da variação observada (COHEN; LEVIN; MOWERY, 1987).

A validade destas últimas observações encontra respaldo na emergência de um novo cenário competitivo em que empresas nascentes e de base tecnológica, denominadas startups, passam a competir com grandes empresas em termos de inovação. Todavia uma análise da relação entre o número de startups de um país e o seu nível de inovação apresentou resultados preocupantes. Observou-se que, nos países desenvolvidos, existe uma relação positiva entre o número de startups e a inovação. Já nos países em desenvolvimento, essa relação não se estabelece, podendo inclusive ser deletéria (ANOKHIN; WINCENT, 2012).

No Brasil, estima-se que existam mais de 10 mil startups, as quais movimentaram, em 2012, cerca de $\mathrm{R} \$ 2$ bilhões. Todavia apenas uma em cada dez startups obtêm sucesso (ASSOCIAÇÃO BRASILEIRA DE STARTUPS, 2014). Uma pesquisa realizada recentemente aponta que $25 \%$ das startups brasileiras não sobrevivem ao primeiro ano de atuação, metade delas desaparece antes de completarem quatro anos de atuação e, entre as que sobrevivem aos quatro anos, 75\% desaparece com menos de 13 anos (ARRUDA et al., 2014). Tendo isso em vista, passa a ser relevante entender quais as capacidades de inovação predominantes em startups, pois isso tende a fornecer indícios das competências centrais para que as startups sejam capazes de inovar e transacionar no mercado.

Estudos que visam avaliar as capacidades de inovação das firmas em setores industriais já são recorrentes na literatura, contribuindo para 0 entendimento das competências essenciais para que uma firma industrial seja capaz de inovar (ZAWISLAK et al. 2012, 2013). Já os estudos sobre startups, entretanto, convergem para uma ênfase voltada à formação de redes de contatos e da localização da startup dentro do cluster, enquanto 0 estudo dos fatores que propiciam a introdução de inovações de sucesso no mercado por parte de startups permanecem pouco explorados na literatura (LEE; LEE; PENNINGS, 2001; PE'ER; KEIL, 2013; ZHENG; LIU; GEORGE, 2010).

Desta forma, tendo em vista as limitações existentes na literatura no que diz respeito a essa perspectiva de análise da temática, questionam-se quais são as capacidades de inovação que predominam em startups? Para responder a essa questão, o estudo objetiva, especificamente, caracterizar e analisar as capacidades de inovação presentes em startups, identificando, entre as quatro capacidades, quais são as que predominam.

Isto posto, justifica-se a relevância do estudo por suas contribuições teóricas e gerenciais. Teóricas, por tentar identificar o conjunto de capacidades predominantes nas startups e de que forma essas capacidades 
contribuem para uma orientação à inovação, contribuições ainda escassas na literatura. Além disso, o diagnóstico das capacidades das startups visa auxiliar gestores a identificar as principais capacidades a serem desenvolvidas para que as startups diminuam as chances de insucesso do negócio por meio da introdução de bens/serviços com maior potencial inovador no mercado.

0 artigo encontra-se estruturado em mais cinco partes: após a introdução, é realizada a revisão da literatura, que aborda as startups em seu contexto e as capacidades de inovação de startups. Na quarta seção é delineada a metodologia de pesquisa. A quinta seção descreve e discute os resultados da pesquisa exploratória. Por fim, na sexta seção, são apresentadas as considerações finais, expondo-se as conclusões mais significativas decorrentes da análise empreendida.

\section{STARTUPS E SEU CONTEXTO}

No cerne de uma startup está, essencialmente, um empreendedor schumpeteriano, que busca o novo e modifica o status quo. Ele possui aptidões que se diferenciam em forma e grau daquelas apresentadas pelo comportamento econômico racional. Observa-se, assim, que não é qualquer indivíduo que pode ser denominado empreendedor, mas sim um tipo muito peculiar, que tem a função de alterar e revolucionar o padrão vigente por meio da exploração de uma invenção ou de uma nova tecnologia (SCHUMPETER, 1985)'.

Startups são consideradas empresas nascentes de base tecnológica, que possuem na inovação tecnológica disruptiva os fundamentos de sua estratégia competitiva. Entre as principais características de tais negócios estão o caráter de organização temporária com potencial de rápido crescimento, os quais atuam em um ambiente de extrema incerteza, em busca de um modelo de negócios que possa tornar-se repetível e escalável (ASSOCIAÇÃO BRASILEIRA DE STARTUPS, 2014; BLANK, 2013). Já uma empresa estabelecida no mercado, ao contrário, está permanentemente projetada para executar um modelo de negócios repetível e escalável, conforme distingue Blank (2013).

Por outro lado, tendo em vista essa incerteza a respeito do modelo de negócio, as startups assumem, pelo menos nos primeiros anos de operação, uma posição indefinida de mercado na busca por oportunidades em nichos de mercado. Todavia essas oportunidades são buscadas por meio do desenvolvimento de produtos ou serviços inovadores de alto valor agregado (FINANCIADORA DE ESTUDOS E PROJETOS, 2014). Ressaltase, ainda, que as startups às quais este estudo se refere são novos negócios surgidos por oportunidade (SCHUMPETER, 1985), e não por necessidade (WENNEKERS et al. 2005).

Entre as principais dificuldades enfrentadas por esses novos negócios empreendedores de alto risco denominados startups estão aquelas relacionadas à pequena disponibilidade de recursos, à menor produtividade e à competição com empresas já estabelecidas no mercado (LERNER, 2010; MASON; BROWN, 2013). Alguns autores argumentam, por exemplo, que a dificuldade das startups de obter e organizar os recursos necessários para a inovação poderia levá-las a conduzir atividades menos complexas, dificultando o desenvolvimento de importantes inovações, além de restringir sua contribuição com o desenvolvimento tecnológico (SHANE, 2010).

Não obstante, as startups também enfrentam limitações relacionadas à sua falta de experiência de mercado: a limitação de ser um recém entrante no mercado (liability of newness), um problema que afeta organizações jovens sem um histórico ou trajetória organizacional (STINCHCOMBE, 1965). Consequentemente, essas organizações carecem de legitimidade organizacional, por exemplo, o que dificulta contratações de novos funcionários ou mesmo negociações com parceiros comerciais e potenciais investidores. Nesse caso, as competências individuais dos empreendedores passam a ser relevantes (SIGMUND; SEMRAU; WEGNER, 2015).

Entre os fatores relevantes à sobrevivência das startups, Arruda et al. (2014) observaram que a aceitação do produto comercializado pelo mercado é um dos fatores mais importantes, além da importância da sintonia entre os fundadores e da capacidade de adaptação dos gestores às alterações de mercado. Já entre os fatores elencados como mais relevantes à descontinuidade da startup estão a falta de comprometimento e a dedicação exclusiva à startup, a falta de alinhamento entre os interesses dos fundadores e a falta de capital para investir no negócio. Por outro lado, o estudo também apontou que startups instaladas em aceleradoras, incubadoras ou parques possuem chances 3,45 vezes menor de descontinuidade do negócio em comparação àquelas que se localizam em escritórios próprios ou alugados.

Outra limitação relacionada às startups refere-se à necessidade de fluxos contínuos de investimentos financeiros, já que elas dificilmente possuem recursos próprios para se autofinanciarem nos anos iniciais de

Revista Alcance - Eletrônica - vol. 23 - n. 1 - jan./mar. 2016 
operação. Para que atraiam os recursos de investidores, as startups passam por um processo de valoração que envolve, entre outros fatores, a análise do quão promissor é o produto ou a tecnologia que está sendo desenvolvida. Entre outros critérios, essas avaliações incluem a capacidade da startup de gerar novos produtos,

ou seja, sua capacidade de inovar (SHANE, 2010).

Embora alguns estudos relacionem a importância do empreendedor ao desempenho da startup, estudos recentes apontam para uma maior influência das capacidades organizacionais sobre o desempenho de empresas (MACIEL, 2009). Não obstante, Maciel (2009) aponta a necessidade de um maior detalhamento das capacidades organizacionais. Nesse sentido, embora no contexto das startups, concentrar-se-á o foco deste estudo na análise das capacidades de inovação de startups, um campo empírico ainda pouco explorado.

\section{AS CAPACIDADES DE INOVAÇÃO DE STARTUPS}

A importância da capacidade de inovação tem sido amplamente discutida na literatura, tendo-se feito importantes avanços no sentido de compreender algumas das capacidades que contribuem para um maior potencial inovador nas empresas (TEECE; PISANO; SHUEN, 1997; GUAN; MA, 2003). No contexto das startups, alguns estudos foram realizados no intuito de compreender quais capacidades maximizam as chances de sucesso de tais organizações, entre os quais destacam-se os de Shan, Walker e Kogut (1994), Deeds, Decarolis e Coombs (1997), Lee, Lee e Pennings (2001), George, Zahra e Wood (2002), Guan e Ma (2003) e Rothaermel e Deeds (2006).

Observa-se, assim, um esforço dos estudos na tentativa de medir tais capacidades a partir da utilização de indicadores referentes às capacidades tecnológicas dessas firmas, como, por exemplo, a qualidade dos recursos humanos e o número de patentes. Contudo essas são variáveis consideradas limitadas pelos próprios autores dos trabalhos, indicando haver a necessidade de um maior detalhamento dessas capacidades em pesquisas futuras (ANOKHIN; WINCENT, 2012; PE'ER; KEIL, 2013; ZHENG; LIU; GEORGE, 2010).

Entende-se, primeiramente, que as capacidades de inovação não se restringem apenas à ideia de capacidades tecnológicas, visto que vantagens competitivas englobam, além do desenvolvimento de inovações tecnológicas, a comercialização dessas tecnologias em uma velocidade mais rápida do que a dos competidores (DECAROLIS; DEEDS, 1999; GUAN; MA, 2003; LEE; LEE; PENNINGS, 2001). Além disso, Guan e Ma (2003) expõem que a ausência de recursos de marketing e de distribuição são as principais dificuldades existentes nas empresas. Desta forma, verifica-se a inexistência de um modelo ou de um conjunto de capacidades consideradas relevantes para as startups, as quais possam auxiliá-las no desenvolvimento de inovações. Tampouco há evidências de que as capacidades das startups com mais de 3,5 anos diferem, ou não, das que estão na fase de pré-comercialização das invenções desenvolvidas.

Constata-se, assim, que mesmo que a capacidade tecnológica da firma seja um importante componente do processo de inovação, ela não explica como as firmas transformam as invenções internas em transações de mercado e, consequentemente, em inovações (ZAWISLAK et al., 2013). Por exemplo, para produzir e, posteriormente, comercializar os novos produtos e/ou processos desenvolvidos internamente, as startups necessitam de capacidades de operação, de gestão e de transação para completar o seu processo de inovação.

Tendo em vista que as barreiras enfrentadas pelas startups dizem respeito não ao desenvolvimento de novas soluções, que poderiam ser medidas por meio de indicadores de patentes, mas sim à operacionalização e à transação do que foi desenvolvido, analisa-se que um modelo de capacidades que englobe a capacidade de desenvolvimento e de operação, mas que perpasse também as capacidades de gestão e de transação, adéquase melhor aos propósitos dessas empresas.

O modelo de capacidades de inovação desenvolvido por Zawislak et al. $(2012,2013,2014)$ no contexto das firmas industriais procura contemplar essas quatro capacidades. Para esses autores, a capacidade de inovação engloba a capacidade de desenvolvimento, de operação, de gestão e de transação, sendo que as duas primeiras correspondem à dimensão tecnológica, enquanto as duas últimas dizem respeito ao eixo de negócios.

A capacidade de desenvolvimento consiste na habilidade de interpretar o estado atual da arte, absorver e, eventualmente, transformar uma determinada tecnologia para criar novos produtos, processos, métodos e técnicas com o objetivo de atingir níveis mais elevados de eficiência técnico-econômica. A capacidade de operação refere-se à habilidade de executar uma dada capacidade produtiva por meio de um conjunto de rotinas diárias, as quais se referem aos padrões de qualidade, à rapidez, à flexibilidade e aos fluxos de trabalho. Já o 
objetivo da capacidade de gestão é transformar as saídas da etapa de desenvolvimento em operações coerentes e em arranjos de transação. A capacidade de transação, por sua vez, compreende a habilidade de reduzir os custos de comercialização, de terceirização, de negociação, de logística e de entrega, ou seja, os custos de transação (ZAWISLAK et al., 2012, 2013). É a partir da análise conjunta dessas capacidades, como apresentado na Figura 1, que é possível observar o desempenho inovativo das firmas e a criação de vantagens competitivas, o qual está condicionado a cada uma das capacidades de inovação.

Figura 1 - Modelo NITEC de Inovação

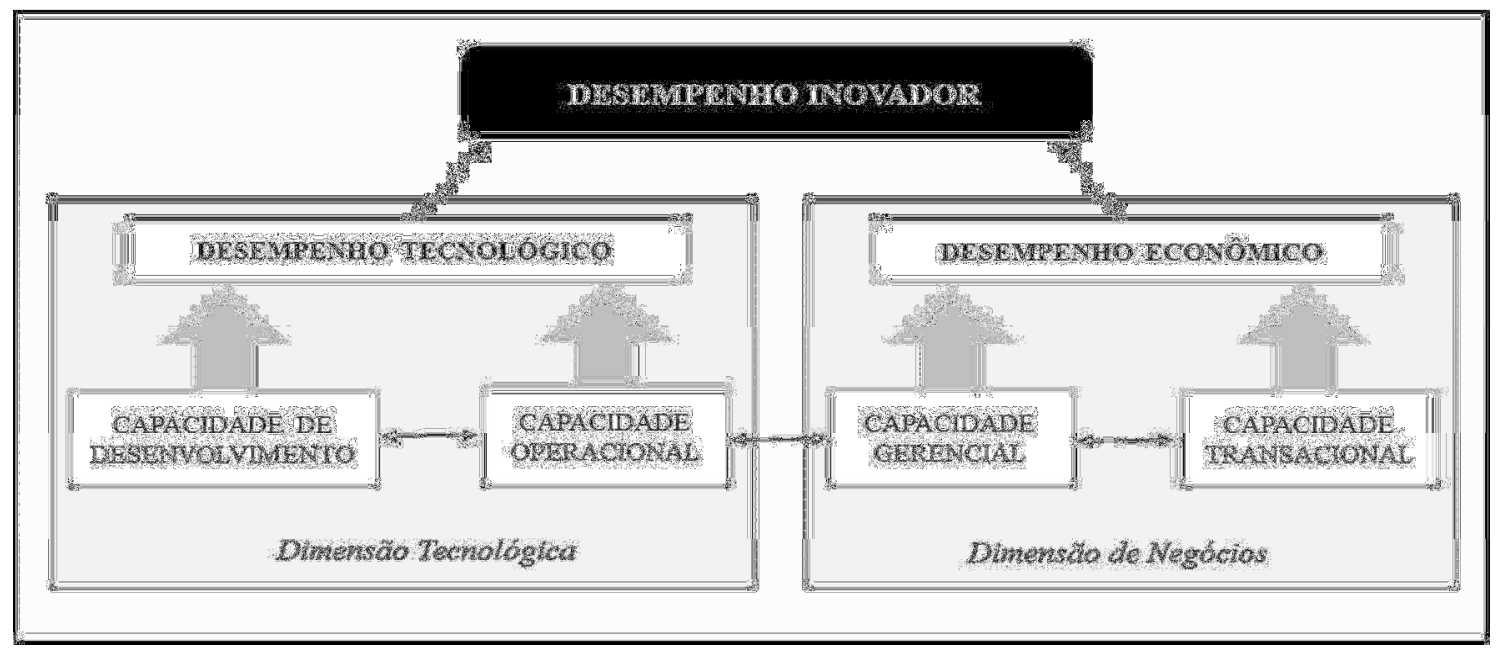

Fonte: Adaptada a partir de Zawislak et al. (2013).

Os diferentes arranjos das capacidades de inovação não explicam apenas a existência das firmas, mas também a heterogeneidade existente entre elas (COCKBURN; HENDERSON; STERN, 2000; PE'ER; KEIL, 2013; RENKO; CARSRUD; BRÄNNBACK, 2009; ZAWISLAK et al., 2012, 2013; ZHENG; LIU; GEORGE, 2010). Isto posto, pressupõe-se que essa heterogeneidade possa ser verificada também entre startups (que ainda estão em fase inicial de operação e transação) e aquelas que já se tornaram firmas (mas que iniciaram as suas atividades como startups), visto que Zheng, Liu e George (2010) afirmam que startups consolidadas há mais tempo possuem rotinas mais robustas as quais lhe possibilitam extrair maior valor econômico de suas inovações quando comparadas às empresas mais jovens.

Além disso, no que compete às diferenças nos arranjos de capacidades ao longo da trajetória de uma firma, Zawislak et al. (2012) propõem que toda a empresa, quando inicia as suas atividades, é inicialmente tecnológica ou transacional e, em uma segunda fase, operacional ou de gestão, o que evidencia as diferentes etapas pelas quais uma empresa passa para ser considerada uma firma no seu sentido econômico. Partindo desse mesmo pressuposto, é possivel que as startups apresentem, também, determinadas configurações predominantes de capacidades, que podem fornecer indícios acerca de como as startups superam as principais limitações encontradas no contexto brasileiro.

Com o intuito de verificar as diferenças nas capacidades de inovação em startups e em firmas são apresentados, na seção subsequente, os procedimentos metodológicos utilizados no estudo.

\section{METODOLOGIA}

0 presente artigo adota o estudo do tipo exploratório, buscando, assim, compreender o contexto geral de um problema ainda pouco explorado. 0 estudo exploratório caracteriza-se por buscar entender as variáveis mais relevantes que precisam ser consideradas em uma pesquisa, possuindo métodos flexíveis, não estruturados e qualitativos, uma vez que os pesquisadores estão abertos às novas ideias e dados (MALHOTRA, 2001; AAKER; KUMER; DAY, 2007).

Optou-se, assim, por realizar um estudo com seis empresas localizadas em Porto Alegre, Rio Grande do Sul: quatro startups e duas firmas. Entre as startups, definiu-se que seriam entrevistadas três em fase de précomercialização do produto/serviço desenvolvido e uma em fase de comercialização do produto (em estágio de

Revista Alcance - Eletrônica - vol. 23 - n. 1 - jan./mar. 2016 
transição para firma). Como firmas, foram selecionadas aquelas empresas com uma trajetória de startup, mas que, atualmente, já possuem um modelo de negócios definido e escalável, a partir do qual estão gerando lucro. O Quadro 1 sintetiza as informações dos entrevistados.

Quadro 1 - Síntese das empresas pesquisadas

\begin{tabular}{|c|c|c|c|c|c|}
\hline \multirow{2}{*}{ Empresa } & \multirow{2}{*}{ Setor de Atuação } & \multicolumn{4}{|c|}{ Perfil do Entrevistado } \\
\hline & & Cargo & Grau de Instrução & Faixa Etária & Gênero \\
\hline Startup A & $\begin{array}{l}\text { Atividades de } \\
\text { Consultoria em } \\
\text { Gestão } \\
\text { Empresarial } \\
\end{array}$ & $\begin{array}{l}\text { Gerente de } \\
\text { Negócios }\end{array}$ & $\begin{array}{c}\text { Graduação em Engenharia } \\
\text { de Produção - UFRGS }\end{array}$ & $20-25$ & M \\
\hline Startup B & $\begin{array}{l}\text { Serviços de } \\
\text { Tecnologia da } \\
\text { Informação }\end{array}$ & $\begin{array}{c}\text { Gerente de } \\
\text { Tecnologia e } \\
\text { Desenvolvimento }\end{array}$ & $\begin{array}{l}\text { Graduação em Ciências da } \\
\text { Computação }\end{array}$ & $30-35$ & M \\
\hline Startup C & $\begin{array}{l}\text { Serviços de } \\
\text { Tecnologia da } \\
\text { Informação }\end{array}$ & $\begin{array}{l}\text { Gerente de } \\
\text { Operações e } \\
\text { Gerente de } \\
\text { Tecnologia }\end{array}$ & $\begin{array}{c}\text { Graduação em Sistemas } \\
\text { de Informação (UFSC) e } \\
\text { Mestrado em Inovação } \\
\text { (UDESC) }\end{array}$ & $25-30$ & M \\
\hline Startup D & $\begin{array}{l}\text { Serviços de } \\
\text { Tecnologia da } \\
\text { Informação }\end{array}$ & Gerente Comercial & $\begin{array}{c}\text { Graduação em Ciências da } \\
\text { Computação (UFRGS) e } \\
\text { Especialização em } \\
\text { Sistemas de Informação } \\
\text { (PUC/RS) }\end{array}$ & $30-35$ & M \\
\hline $\begin{array}{c}\text { Empresa } \\
\text { A }\end{array}$ & $\begin{array}{l}\text { Serviços de } \\
\text { Tecnologia da } \\
\text { Informação }\end{array}$ & $\begin{array}{l}\text { Gerente de } \\
\text { Negócios }\end{array}$ & $\begin{array}{c}\text { Graduação em } \\
\text { Administração de } \\
\text { Empresas (Un. São Judas } \\
\text { Tadeu) } \\
\end{array}$ & $30-35$ & $\mathrm{~F}$ \\
\hline $\begin{array}{c}\text { Empresa } \\
B\end{array}$ & $\begin{array}{l}\text { Saúde Humanal } \\
\text { Fabricação de } \\
\text { Produtos Químicos } \\
\text { e Farmacêuticos }\end{array}$ & Diretor Presidente & Graduação em Farmácia & $40-45$ & M \\
\hline
\end{tabular}

Fonte: Elaborado pelos autores.

$\mathrm{Na}$ etapa de coleta de dados, buscaram-se diferentes fontes de informações, como, por exemplo, documentos e entrevistas em profundidade, as quais são consideradas fundamentais em estudos qualitativos e indicadas quando se deseja obter maior compreensão sobre aspectos que envolvem o meio no qual o respondente se encontra (ROESCH, 2009). Os documentos foram coletados a partir do website das empresas, sendo essa uma fonte institucional de informações. Já as entrevistas tiveram por base um roteiro semiestruturado, o qual era composto de três blocos de questões: características gerais, capacidades de inovação (desenvolvimento, operação, gestão e transação) e fatores externos. Todas as entrevistas foram gravadas e, posteriormente, transcritas.

A análise dos dados levantados e das entrevistas realizadas foi feita com base na técnica da Análise de Conteúdo, a qual consiste, basicamente, em um conjunto de técnicas de análises de comunicações que objetivam ultrapassar as incertezas e enriquecer a leitura dos dados coletados (BARDIN, 2006). Desta forma, Bardin (2006) cita três etapas compreendidas pela técnica: (a) pré-análise; (b) exploração do material; e (c) tratamento dos resultados, inferência e interpretação. 0 esquema conceitual que fundamentou a aplicação da técnica foi adaptado a partir de Zawislak et al. (2014).

\section{ANÁLISE E DISCUSSÃO DOS RESULTADOS}

A presente seção tem como objetivo analisar e discutir os resultados dos dados coletados na pesquisa exploratória. Para tanto, são apresentados, primeiramente, os resultados referentes às startups, para, em 
seguida, serem expostos os contextos das firmas que nasceram como startups, mas que já se encontram consolidadas no mercado. Por fim, é empreendida uma análise que visa comparar os dois estágios desses dois diferentes grupos de empresas com o intuito de identificar quais são as capacidades de inovação predominantes em startups.

\subsection{As startups}

\section{Startup A}

A startup $A$, entre as analisadas, é a que se encontra no estágio mais incipiente. $O$ objetivo dessa startup consiste em ser uma empresa de inteligência em treinamento para franquias. A ideia teve origem na percepção dos sócios, os quais observaram a alta rotatividade existente entre os funcionários de franquias.

Isto posto, os dois sócios optaram por criar uma startup de consultoria em gestão empresarial, na qual será desenvolvido um sistema on-line de treinamento de acordo com os processos internos necessários para se executar uma função de uma determinada franquia. Paralelamente, está sendo desenvolvido um game para treinamento, o qual poderá ser agregado como uma das ferramentas da atividade de consultoria. Analisa-se, assim, que essa startup, atualmente, está prospectando possíveis parceiros para poder operacionalizar a primeira versão do seu projeto, o qual ainda não está consolidado.

No âmbito específico das capacidades de inovação, observa-se que um dos sócios se dedica ao desenvolvimento do produto/serviço, enquanto o outro é responsável pela área de negócios, especificamente por mapear e contatar possíveis clientes. Apesar de, no atual momento, todos os esforços estarem centrados na busca por parcerias com franquias, ou seja, na sua capacidade transacional, os sócios afirmam que, no futuro, querem ser reconhecidos pela sua capacidade de desenvolvimento de ferramentas inovadoras que auxiliam no treinamento de pessoas.

Por conseguinte, as capacidades de operação e de gestão ainda são inexistentes. Essa constatação justifica-se no fato de que a startup ainda não possui processos e atividades formalizadas. A operacionalização será iniciada apenas mediante o fechamento do primeiro contrato, visto que, por se tratar de um serviço, a operacionalização e sua comercialização ocorrem ao mesmo tempo. Já a gestão das atividades ainda não se encontra estruturada, sendo que processos referentes à gestão de pessoas ainda não se fazem necessários, enquanto questões financeiras ainda não foram estrategicamente discutidas e elaboradas pelos sócios. Não há uso de softwares até o momento, e toda a comunicação ocorre verbalmente entre os fundadores.

\section{Startup B}

A startup B foi criada com o objetivo de desenvolver um software para transportadoras e embarcadores que buscam caminhoneiros autônomos para o transporte de cargas. No país, atualmente, $60 \%$ do transporte total de cargas é realizado por caminhoneiros autônomos, os quais, geralmente, têm o seu serviço contratado pelas transportadoras ou pelas embarcadoras. Assim, o software visa promover o encontro on-line entre transportadoras e embarcadores, que estão buscando alguém para efetuar o transporte de uma determinada carga, e caminhoneiros autônomos que realizam esse serviço.

A ideia que deu origem a essa startup nasceu no final de 2013, mas só foi viabilizada a partir de março de 2014 em um processo de pré-incubação no Centro de Empreendimentos em Informática da Universidade Federal do Rio Grande do Sul (UFRGS). Posteriormente, o projeto da startup foi contemplado no Startup Brasil, o que a vinculou a uma aceleradora. Atualmente, a startup B encontra-se na etapa de desenvolvimento do produto/serviço a ser comercializado. A primeira etapa de teste será realizada com uma única transportadora e os caminhoneiros que ela possui cadastrados em seu banco de dados. A segunda etapa englobará mais duas transportadoras, sendo que o objetivo era lançar, no mercado, o produto até o final do ano de 2015.

Analisa-se, assim, que a capacidade predominante nessa startup é a capacidade de desenvolvimento, visto que todos os esforços de inovação dela encontram-se atrelados ao desenvolvimento do produto a ser comercializado. Essa constatação encontra respaldo quando se observa a composição da atual equipe de trabalho. A startup conta, hoje, com três programadores e um designer de interface gráfica, além dos dois sócios, sendo um responsável pela área de tecnologia e desenvolvimento e o outro encarregado da área de negócios. Além disso, a principal vantagem competitiva que a startup pretende criar frente aos seus concorrentes é por meio da inclusão de outros serviços ao produto, como, por exemplo, o serviço de

Revista Alcance - Eletrônica - vol. 23 - n. 1 - jan./mar. 2016 
rastreamento do veículo que está transportando a carga e a possibilidade de troca de mensagens entre a empresa e o caminhoneiro. Isso permitirá à startup agregar valor ao produto, mas também lhe exige mais capacidade para desenvolver e incluir essas soluções à sua oferta.

Já as demais capacidades podem ser consideradas incipientes ou inexistentes. A capacidade de operação ainda é inexistente, pois a empresa ainda não iniciou as suas operações, nem mesmo a fase de teste do seu produto. A capacidade de gestão encontra-se restrita à estruturação das atividades a serem executadas, sendo que as responsabilidades ainda são compartilhadas entre toda a equipe, não havendo uma estrutura formal de divisão de tarefas. Observa-se, também, que o plano de negócios ainda está indefinido, sem uma forma de monetização definida, tampouco com valores e estrutura de custos definida. Todavia se observou que esse processo é comum nesse estágio da etapa do desenvolvimento do produto de startups. No entanto, verifica-se que está sendo elaborado um plano de marketing para definir as estratégias referentes aos canais de distribuição e às potenciais formas de relacionamento com os clientes. Apesar de incipiente, a capacidade transacional também demanda um esforço inovativo, dado que os seus concorrentes estão focados principalmente em oferecer um serviço para as transportadoras e para os embarcadores, enquanto o foco da startup são os caminhoneiros autônomos. Para isso, a empresa terá que formular novas estratégias por meio de alianças com postos de gasolina e empresas de cartão de frete para conseguir atingir esse público em específico.

\section{Startup C}

A startup C está desenvolvendo um aplicativo que permite efetuar pedidos de água mineral em galões de 20 litros. $O$ canal de comercialização de água mineral possui, em média, de três a cinco níveis: uma envasadora que vende para a distribuidora, que revende para o disque água, que, por sua vez, vende ao consumidor final. A startup, assim, se insere entre o disque água e o consumidor final. Primeiramente, os sócios realizaram algumas entrevistas para avaliar a viabilidade do negócio e a adequação da ideia ao mercado, iniciando, em uma fase seguinte, o desenvolvimento do aplicativo.

Concomitantemente ao desenvolvimento do aplicativo, os fundadores da startup desenvolveram parcerias com distribuidoras de água para que o aplicativo pudesse ser testado e aperfeiçoado. Além disso, os entrevistados destacaram a importância na rapidez do desenvolvimento do aplicativo para validação no mercado, mesmo que ele esteja ainda em uma versão bruta e parcialmente finalizada. Segundo eles, funcionalidades podem ser agregadas ao aplicativo à medida que o mercado for manifestando determinadas necessidades, seguindo uma lógica de startup enxuta (BLANK, 2013).

A capacidade predominante da startup é a de desenvolvimento. A startup tem como base de conhecimento a tecnologia da informação, sendo um facilitador o fato de que todos os sócios da empresa possuem formação nessa área do conhecimento. A startup consegue, assim, disponibilizar um produto (água mineral) de modo mais cômodo (por meio de tele-entrega), rápido e prático no mercado.

A capacidade transacional é a segunda mais desenvolvida da empresa, tendo em vista que a startup está começando a se relacionar com fornecedores e clientes no mercado. De acordo com os sócios da empresa, durante os próximos meses serão buscados novos parceiros e fornecedores de modo que o negócio seja viável e vantajoso para todos.

Por outro lado, a startup carece de capacidade operacional que the permita atingir escala, visto que 0 produto ainda não foi disponibilizado no mercado. Entre a prática da startup está a confirmação, por telefone, do recebimento do pedido pelo disque água. Essa prática é considerada necessária pelos sócios da startup durante o período inicial de operação, dado que alguns disque água ainda não possuem computador. Em uma segunda fase da operação, o disque água receberá os e-mails com os pedidos dos clientes. Nessa etapa, continuará sendo necessário o envolvimento da startup no processo de confirmação do recebimento dos pedidos, tendo em vista que existe o risco destes estabelecimentos não visualizarem os e-mails recebidos. Em uma terceira fase, na de lançamento do aplicativo, haverá pouco envolvimento operacional da startup, pois é a fase na qual o disque água visualizará os pedidos recebidos em uma plataforma on-line.

A capacidade de gestão, por fim, é a menos desenvolvida (sendo quase inexistente), pois as operações ainda não estão consolidadas, tampouco o método de coordená-las. Existe, assim, uma divisão de tarefas informal entre os sócios da empresa, na qual cada um é responsável por uma grande área: um pela de operações e outro pela área de tecnologia. Todavia a equipe que compõe a startup foi considerada, pelos 
sócios, um dos fatores determinantes para o sucesso da startup.

\section{Startup D}

A startup D, que desenvolveu um aplicativo para gerenciamento de condomínios, já se encontra em fase de comercialização e expansão de mercado. $O$ aplicativo desenvolvido é uma ferramenta que possibilita, por meio de uma plataforma on-line, a discussão de pautas comuns em condomínios, além de permitir o agendamento e a reserva de espaços. 0 diferencial da empresa, que conta com quatro concorrentes do mesmo nível tecnológico, é permitir a personalização das funcionalidades e a adaptação do aplicativo de acordo com as necessidades e regras específicas do condomínio. A referida empresa possui cerca de 10 mil clientes finais (casas), distribuídos em, aproximadamente, 60 condomínios. Embora a venda do software seja negociada com 0 síndico, cada morador do condomínio paga uma mensalidade individual.

A capacidade predominante da empresa em questão é a de desenvolvimento, visto que o aplicativo foi elaborado pelos sócios, os quais possuem formação em ciências da computação. A personalização do aplicativo de acordo com as necessidades de cada condomínio (dentro de padrões aceitáveis) demanda conhecimentos relacionados à capacidade de desenvolvimento tecnológico, pois diferentes solicitações de clientes geram adaptações e mudanças no produto.

A segunda capacidade mais desenvolvida é a de transação, por meio da qual relações e parcerias estão sendo estabelecidas. A empresa vem estreitando seus relacionamentos com síndicos e grandes condomínios, além de estar buscando se aproximar também de administradoras de condomínios. No caso das administradoras, como o número de residências abrangidas é muito maior em comparação às de um condomínio, pode haver uma flexibilização nos valores cobrados pela empresa no fechamento do contrato. Todavia nada impede que a administradora cobre valores diferenciados de cada um dos condomínios, o que fica então a seu critério.

A capacidade operacional, que se baseia no conhecimento prévio e nas habilidades dos fundadores da startup, encontra-se em nível intermediário, pois ainda não existem rotinas diárias definidas e não há um planejamento das operações. Não obstante, as adaptações realizadas em cada condomínio tendem a dificultar a escalabilidade futura do aplicativo. Nesse sentido, é um desafio para a startup encontrar um nível de personalização que não comprometa a operacionalização e a escalabilidade. A capacidade menos desenvolvida da startup é a capacidade de gestão. Contudo ela possui um nível mínimo dessa capacidade, pois é ela que permite transformar os processos internos em um produto que possa ser comercializado no mercado. Contudo é reconhecida, pelo entrevistado, a necessidade de aprimorar, principalmente, a gestão financeira na empresa.

\subsection{As Firmas}

\section{Empresa A}

A empresa A, por sua vez, iniciou as suas atividades em 2003 como uma startup, tendo como produto ofertado o SMS corporativo para comunicação e marketing. Na época, o produto era considerado uma inovação e foi o que permitiu com que a empresa se consolidasse no mercado, sendo hoje líder de mercado em serviços de mobilidade no Brasil. Em parte, esse crescimento se deve às aquisições realizadas a partir de 2011, o que permitiu a expansão do portfólio de produtos ofertados.

Apesar de pertencer ao setor de Tecnologia da Informação, a gestora da área comercial afirma que o principal produto comercializado pela empresa ainda corresponde ao SMS corporativo. Seus principais clientes estão localizados na região Sul e Sudeste, com destaque para as empresas de recuperação de crédito, da área da saúde e do varejo. A empresa atua tanto no atendimento de clientes de pequeno e médio porte, os quais representam $48 \%$ do seu faturamento; como no atendimento de empresas de grande porte, as quais são responsáveis pelos outros $52 \%$ do faturamento.

No que concerne às suas capacidades, constata-se que a empresa $A$ sempre se destacou pela sua capacidade transacional, tendo como diferencial competitivo a proximidade com os seus mais de 4.500 clientes e fornecedores, os quais correspondem às operadoras de telefonia móvel no Brasil. Por ser uma empresa homologada, possui o direito de negociar diretamente com as operadoras, não sendo necessário adquirir serviços de outras empresas intermediárias. Ademais, a empresa possui clientes de diferentes portes, o que lhe assegura um volume considerável de compra de pacotes de mensagens SMS. Como estratégia futura, a

Revista Alcance - Eletrônica - vol. 23 - n. 1 - jan./mar. 2016 
empresa visa aumentar o volume de vendas por cliente, expandir a sua atuação na região Nordeste e captar mais clientes de médio porte.

Já no que diz respeito a sua capacidade de desenvolvimento, observa-se que, apesar de possuir um nível de desenvolvimento tecnológico semelhante ao dos seus concorrentes, essa capacidade esteve atrelada, nos últimos quatro anos, às aquisições realizadas (de outras startups, inclusive). A criação de uma área interna de inovação só passou a ser discutida e planejada recentemente, motivo pelo qual a atual capacidade de desenvolvimento da empresa não pode ser considerada predominante. Como estratégia para alavancar essa capacidade, a empresa visa utilizar o aporte de capital, recebido em 2014, no valor de R $\$ 71$ milhões. Esses recursos serão destinados, principalmente, para a aquisição de empresas e startups com tecnologias complementares, bem como para investir na criação e no desenvolvimento interno de produtos inovadores.

A capacidade de gestão, praticamente inexistente na época em que a startup foi criada, hoje exige da empresa a estruturação de processos, bem como a sua formalização e documentação. Os principais fatos que justificaram o investimento nessa capacidade foram as aquisições realizadas e o crescimento da empresa como organização, sendo que a empresa atualmente conta com, aproximadamente, 120 funcionários. Por conseguinte, a área de operações é responsável por executar as rotinas de produção, sendo que o sistema utilizado no serviço de SMS corporativo é basicamente o mesmo de 2003, com algumas melhorias e novas versões. Assim, essa capacidade demanda poucos esforços inovativos.

\section{Empresa B}

Por fim, a empresa de radiofármacos $\mathrm{B}$, que conta com cerca de 60 funcionários, fabrica produtos com aplicação para cintilografia. $O$ negócio originou-se de uma oportunidade de mercado decorrente da saída de fornecedores multinacionais do Brasil. Primeiramente, o conhecimento adquirido na área da farmácia permitiu que 0 fundador prestasse consultorias e treinamentos a hospitais no que concerne ao preparo das substâncias. Entre 2004 e 2006, com o apoio de um investidor anjo, foi possível montar um laboratório dentro de uma incubadora, que, em 2008, estava validado e já tinha o primeiro produto desenvolvido.

A empresa B originou-se como uma incubada dentro de uma área física de uma empresa já graduada, tendo em vista a impossibilidade de transferir e realocar um laboratório de um local para outro. Contudo o fundador reconhece que o relacionamento da empresa com o parque inicialmente se restringia à locação de área, sendo que apenas nos dois últimos anos isso tem mudado em função de uma maior qualificação profissional ocorrida na região. Antes disso, as vantagens eram muito mais relacionadas à credibilidade obtida por ter a imagem e o nome vinculados ao da instituição de ensino.

A capacidade predominante da empresa B é a de desenvolvimento. Nesta capacidade incluem-se não apenas a capacidade de desenvolver novos radiofármacos, mas também de ampliar seu modelo de negócio. Atualmente, a empresa está reestruturando sua área de consultoria, tendo em vista que muitos problemas de imagem em exames são oriundos de preparos feitos incorretamente por técnicos. Com relação ao desenvolvimento de novos produtos, a partir de 2012 a empresa começou a desenvolver atividades relacionadas à inovação. Entretanto, como o processo de desenvolvimento de um produto novo é longo e complexo no Brasil em função da escassa infraestrutura de suporte, a empresa contatou importantes universidades na Alemanha e nos Estados Unidos que desenvolvem produtos para a medicina nuclear e propuseram o pagamento de royalties pelo uso da tecnologia. A empresa busca, assim, produtos que estejam na fase final de seu desenvolvimento. Esse modelo de negócio foi escolhido considerando que, no Brasil, não existem universidades fazendo pesquisas com radiofármacos, tampouco existem laboratórios habilitados a realizar testes de fase 1 (obrigatórios pelos protocolos internacionais).

Observa-se, sobretudo, que a capacidade de desenvolvimento da empresa B é facilitada pelas parcerias internacionais, que permitem a rápida colocação de produtos no mercado. A ideia de ter um desenvolvimento de produtos próprio, como um laboratório que desenvolve novas moléculas, é um projeto previsto para ser iniciado a partir de 2016/2017.

A capacidade operacional está sendo reestruturada com a construção de uma nova fábrica. Os lotes fabricados pela empresa, atualmente, são pequenos em função da especificidade de sua aplicação, sendo que cada lote tem um período médio de 36 horas para ser finalizado. 0 processo seguinte é o de controle de qualidade que dura 14 dias, no qual se verifica a eventual proliferação de bactérias. Desta forma, entre a abertura de uma ordem de produção e o seu fechamento decorrem cerca de 30 dias, que é o prazo mínimo 
possível. Maiores ganhos podem ser obtidos com o aumento do número de frascos por lote, o que reduz os custos por lote. Segundo o sociofundador da empresa, existe demanda para esse aumento de produção por meio da exportação, que a empresa pretendia iniciar como um projeto piloto a partir de 2015.

No que diz respeito à capacidade de gestão da empresa $B$, analisa-se que a participação do fundo de investimentos na empresa contribuiu consideravelmente para a melhoria da gestão. Com a entrada do fundo, a empresa foi departamentalizada, organizada e estruturada internamente, tendo-se verificado um aumento da burocratização. Além disso, aspectos como cultura, missão, visão e valores também estão sendo alinhados, juntamente com iniciativas para reverter a baixa retenção de funcionários. Já a opção de instalar a empresa dentro de um parque tecnológico justifica-se no fato de que nesse tipo de ambiente os processos burocráticos são mais ágeis. A capacidade de gestão e a capacidade operacional da empresa estão alinhadas na empresa, não havendo a sobreposição de uma ou de outra. Segundo o próprio entrevistado, existe uma necessidade de que ambas permaneçam em equilíbrio para que a empresa desempenhe suas atividades com coerência.

Das capacidades, a transacional é a menos desenvolvida. A fraqueza é reflexo da área comercial ter sido transferida para São Paulo, o que a tornou um pouco desvinculada do restante da empresa, do próprio perfil e da sua cultura. Nos relacionamentos com fornecedores predominam as parcerias, sendo essas relações com fornecedores e clientes consideradas muito boas pelo entrevistado, talvez por ter se originado como uma empresa que disponibiliza consultores formados em biomedicina para visitar clientes e ensinar os técnicos a preparar as substâncias. Mesmo assim, a maior parte dos clientes prefere produtos de preço baixo e de menor qualidade. Em termos de participação no mercado, em relação ao portfólio total de produtos, a empresa possui cerca de $40 \%$ de participação no mercado de radiofármacos em geral, embora esteja limitada pela sua pequena capacidade instalada atualmente.

\subsection{A análise das capacidades predominantes}

As entrevistas realizadas permitiram a identificação das capacidades de inovação predominantes nas startups e nas firmas. Observou-se que a capacidade de desenvolvimento e a capacidade transacional foram as capacidades predominantes, tanto nas startups quanto nas firmas. Todavia, ressalta-se que, nas startups, a capacidade de desenvolvimento é predominante sobre a capacidade transacional, enquanto o mesmo não ocorre necessariamente nas firmas, como evidenciado pelo caso da empresa $B$.

A aceitação do bem/serviço pelos clientes é crucial para o sucesso futuro do negócio, sendo uma das principais preocupações dos entrevistados, evidência que corrobora o estudo de Arruda et al. (2014), no qual os autores afirmam ser esse um dos fatores que justifica a sobrevivência das startups em sua fase inicial. Nesse sentido, o entrevistado da startup $C$ explica estar realizando o desenvolvimento do aplicativo de modo interativo com o usuário, o que possibilita eventuais ajustes. Assim, além dos conhecimentos técnicos, é necessário que 0 fundador seja capaz de interpretar as informações e as exigências do mercado, adaptando seu modelo de negócios coerentemente. Estas competências encontram-se relacionadas à capacidade de desenvolvimento, a mais importante nos primeiros anos da startup, e também a predominante em todas as startups entrevistadas. A partir do relato das empresas A e B, identificou-se que a capacidade de desenvolvimento constituiu capacidade central a partir da qual o negócio foi construído e desenvolvido. Analisa-se que o conhecimento, as habilidades e as experiências dos fundadores são relevantes para a construção dessas capacidades, como já destacado por Zawislak et al. (2012).

A segunda capacidade com maior destaque nas startups é a transacional, por meio da qual são construídas as redes de relacionamentos com potenciais clientes, consumidores e fornecedores. Nesse sentido, constata-se que os resultados da pesquisa corroboram com o que já havia sido apontado pela literatura referente à temática, ou seja, que a rede de relacionamentos das startups é um dos fatores de maior importância nos primeiros anos do empreendimento, já que é o momento em que a startup precisa obter contatos para transacionar no mercado (ZHENG; LIU; GEORGE, 2010).

Neste aspecto, a aceleradora parece exercer papel fundamental, sendo mais bem avaliada em relação à incubadora. $O$ fato de três das startups estarem sendo aceleradas permite-lhes expandir a sua rede de contatos, auxiliando-as a contatar possíveis clientes, bem como investidores. $O$ contato com investidores auxilia, assim, a minimizar as dificuldades decorrentes da pequena disponibilidade de recursos que esse tipo de empresa possui, sendo esse um dos obstáculos citados por Shane (2010), Lerner (2010) e Mason e Brown (2013) e observado por Arruda et al. (2014) em um recente estudo sobre as startups brasileiras. Pode-se dizer, então, que é por meio da capacidade transacional que a startup obtém importantes recursos financeiros, uma

Revista Alcance - Eletrônica - vol. 23 - n. 1 - jan./mar. 2016 
das limitações destas organizações.

Observou-se, também, a partir do relato do entrevistado da empresa B, que problemas enfrentados por startups, relacionados à liability of newness, são minimizados por meio da capacidade transacional. Neste caso, o relacionamento com determinadas instituições, como a universidade à qual a startup esteve ligada desde 0 início, conferiu a ela legitimidade organizacional para realizar transações no mercado, firmar parcerias com importantes fornecedores e obter seus primeiros clientes. Observou-se, então, que aspectos como falta de legitimidade organizacional foram minimizados, neste estudo, por meio do estabelecimento de relacionamentos com determinadas instituições.

Adicionalmente, analisa-se também que, das quatro startups analisadas, apenas uma delas está iniciando suas atividades de forma independente, sem apoio de uma aceleradora ou incubadora de empresas. Essa foi uma escolha dos fundadores que consideraram não necessitar do apoio proporcionado por essas instituições. Todavia se verificou que tal startup encontra-se em meio a um estágio muito incipiente do modelo de negócio (indefinição de nome, como será capturado valor, indefinições de aspectos operacionais básicos), ao mesmo tempo em que está tentando negociar o fechamento de seu primeiro contrato com uma rede de franquias. Não obstante, o desenvolvimento de dois produtos concomitantemente, como a startup vem fazendo, não tende a ser uma estratégia adequada quando os recursos financeiros e humanos são escassos.

Por outro lado, as outras três startups entrevistadas estão sendo aceleradas. Uma delas, que já havia participado de um processo de incubação, afirmou ter saído daquele modelo pela falta de dinamismo proporcionado pela incubadora, embora tenham recebido um importante apoio na formulação do plano de negócios. As startups aceleradas destacam a acessibilidade a investidores, os workshops direcionados às necessidades das startups e o contato com os profissionais de outras startups como sendo alguns dos aspectos muito importantes para o seu desempenho, bem como a importância do alinhamento da equipe de trabalho. Predominantemente, percebe-se que as aceleradoras contribuem com o desenvolvimento da capacidade transacional da startup, ao aproximá-las de potenciais investidores e de potenciais clientes.

Com relação à capacidade operacional, a maior dificuldade verificada durante as entrevistas diz respeito à escalabilidade futura do modelo de negócio adotado pelas startups. Embora esse seja, reconhecidamente, o maior desafio de uma startup, entende-se que realizar customizações ou desenvolver soluções regionais não são uma forma de atingir escala. Sabe-se, contudo, que startups alteram aspectos do modelo de negócio com frequência, embora nem todas as startups consigam fazê-lo, por carecerem de capacidades e competências para tal.

Os entrevistados apontaram também a relevância do trabalho em equipe, da sintonia entre os fundadores da startup e a capacidade de adaptação dos gestores às mudanças, tal qual apontado por Arruda et al. (2014) e Blank (2013). Essas capacidades, juntamente à documentação de processos, formalização de procedimentos, gestão financeira e de recursos humanos compõem a capacidade de gestão, que se mostrou a menos predominante entre todas as capacidades.

Embora as capacidades de operação e de gestão sejam incipientes, ou até mesmo inexistentes em algumas startups, percebe-se que, à medida que a startup torna-se mais complexa no sentido de comercializar seu produto no mercado, ela tende a tornar mais complexa sua operação e sua gestão. $A$ empresa $B$, por exemplo, relata a profissionalização da gestão a partir do recebimento de capital de um investidor. Esse processo, comumente relatado por startups, é relevante, já que a expansão da organização conduz, naturalmente, a uma desorganização, à medida que não existem processos documentados, descrições de cargos ou procedimentos claros. Ainda com relação à gestão, as startups utilizam modelos de negócios CANVAS, em contraste aos modelos e aos planos de negócios formais. 0 uso do modelo CANVAS é recomendado em função da natureza do negócio destas organizações, que pode sofrer alterações semanais ou até mesmo diárias (BLANK, 2013).

Com relação às empresas $A$ e $B$, observou-se que elas possuem as quatro capacidades bem desenvolvidas. De acordo com os relatos, as firmas consolidadas parecem ter desenvolvido, de modo gradual, as capacidades de desenvolvimento, transação, operação e gestão. Essas capacidades foram desenvolvidas à medida que as empresas foram se expandindo, evidenciando-se que a capacidade de gestão é desenvolvida concomitantemente e complementarmente à de operação. A partir do relato do entrevistado da empresa $\mathrm{B}$, verifica-se que ambas as capacidades estão igualmente desenvolvidas na empresa, o que é necessário para que ela desempenhe suas atividades sem percalços.

As capacidades de inovação, principalmente a de desenvolvimento e de transação, aparentam ser 
relevantes para que a startup supere as limitações encontradas nos primeiros anos de operação. Acredita-se que 0 desenvolvimento das capacidades de operação e de gestão ocorra em decorrência da própria expansão da startup. $O$ conjunto das quatro capacidades de inovação passa, então, a ser relevante no processo de crescimento da startup, no qual ela se torna um agente econômico e passa a transacionar no mercado e comportar-se como uma firma.

Ademais, analisa-se que as startups realmente nascem de uma capacidade de inovação tecnológica ou transacional, passando apenas, em um segundo momento, a desenvolver a sua capacidade de inovação operacional ou de gestão, como proposto por Zawislak et al. (2012). Quando comparadas as startups com as firmas, é possível verificar que, mesmo a capacidade de desenvolvimento sendo predominante, a capacidade transacional já é pautada dentro da estratégia da startup, sendo desenvolvida concomitantemente em alguns casos. Essa necessidade de transacionar no mercado fundamenta-se na lógica de procurar obter não apenas retornos rápidos quanto ao produto desenvolvido, mas também a validação do mercado para o produto. Se a tecnologia não for bem aceita, o produto é adaptado para refletir os interesses do mercado consumidor.

De acordo com o observado, a capacidade de operação e de gestão são as capacidades menos desenvolvidas em uma startup. Essas duas capacidades passam a integrar as rotinas de uma startup na medida em que ela se consolida como firma e quando a empresa cresce como organização, conforme já apontado por Zawislak et al. (2012).

As evidências também demonstraram que as startups possuem certo nível de capacidade transacional desenvolvida, o que expõe a limitação de estudos que abordam a capacidade de inovação apenas na sua perspectiva tecnológica, desconsiderando a dimensão de negócios, como apontado por outros autores como Anokhin e Wincent (2012), Pe'er e Keil (2013) e Zheng, Liu e George (2010). Indicadores como, por exemplo, o número de patentes, se utilizados no presente estudo, seriam irrelevantes, dado que nenhuma das empresas entrevistadas possui registros de patentes. As patentes, em determinados contextos, pouco são respeitadas, além de onerarem e engessarem a organização, como aponta 0 entrevistado da startup $C$ e da empresa $B$. Destaca-se, assim, a importância de adotar um modelo que seja mais abrangente e adequado à realidade das startups, ou mesmo de algumas empresas de tecnologia, como o modelo de Zawislak (2012, 2013, 2014).

Não obstante, verifica-se uma nítida heterogeneidade entre as startups e as firmas. Parte dessa heterogeneidade pode ser atribuída aos diferentes arranjos de capacidades de inovação (COCKBURN; HENDERSON; STERN, 2000; PE'ER; KEIL, 2013; RENKO; CARSRUD; BRÄNNBACK, 2009; ZAWISLAK et al., 2012, 2013; ZHENG; LIU; GEORGE, 2010). Enquanto nas startups existem, muitas vezes, apenas a capacidade de desenvolvimento e de transação, nas firmas existem as quatro capacidades. Ademais, observa-se que, nas firmas, a capacidade de operação e de gestão apresenta-se tão ou mais relevantes quanto as demais; enquanto nas startups elas são inexistentes ou incipientes.

Por fim, enfatiza-se que, das startups entrevistadas, apenas uma possuía uma ideia inovadora e que ainda não possui concorrentes; enquanto as demais baseiam-se em modelos de negócios já validados em outros países ou que já existem mesmo dentro do Brasil. Desta forma, a própria formação dos sócios de uma startup acaba ditando a natureza da startup criada, as quais geralmente não usufruem dos spillovers de conhecimento gerados pelas universidades, distanciando-se, assim, da possibilidade de interagirem com universidades ou centros de pesquisa. A Figura 2 apresenta uma síntese da análise. 
Figura 2 - Síntese da análise

\begin{tabular}{|c|c|c|c|}
\hline Desenvolvimento & Operação & Gestão & Transação \\
\hline $\begin{array}{l}\text { - Capacidade } \\
\text { predominante nas } \\
\text { startups, mas não nas } \\
\text { firmas; } \\
\text { - Aceitação do } \\
\text { bem/serviço é crucial } \\
\text { para o sucesso do } \\
\text { negócio, motivo pelo } \\
\text { qual algumas startups } \\
\text { realizam o } \\
\text { desenvolvimento de } \\
\text { modo interativo com o } \\
\text { usuário; } \\
\text { - O conhecimento, as } \\
\text { habilidades e as } \\
\text { experiências dos } \\
\text { fundadores são } \\
\text { importantes; } \\
\text { - O desenvolvimento, } \\
\text { em paralelo, de dois } \\
\text { produtos não parece } \\
\text { ser adequado para uma } \\
\text { startup. }\end{array}$ & $\begin{array}{l}\text { - A maior } \\
\text { dificuldade } \\
\text { encontrada diz } \\
\text { respeito à } \\
\text { escalabilidade } \\
\text { futura do negócio; } \\
\text { - Realizar } \\
\text { customizações e } \\
\text { desenvolver } \\
\text { soluções regionais } \\
\text { não contribuem } \\
\text { para a obtenção } \\
\text { de escala; } \\
\text { - À medida que } \\
\text { ocorre a } \\
\text { comercialização } \\
\text { do produto, a } \\
\text { operação torna-se } \\
\text { mais complexa. }\end{array}$ & $\begin{array}{l}\text { - A capacidade menos } \\
\text { desenvolvida entre } \\
\text { startups e firmas; } \\
\text { - O trabalho em equipe e } \\
\text { a adaptação a mudanças } \\
\text { são importantes; } \\
\text { - A documentação de } \\
\text { processos, formalização } \\
\text { de procedimentos, gestão } \\
\text { financeira e de recursos } \\
\text { humanos são pouco } \\
\text { desenvolvidas; } \\
\text { - À medida que ocorre a } \\
\text { comercialização do } \\
\text { produto, a gestão torna- } \\
\text { se mais profissional; } \\
\text { - Startups utilizam } \\
\text { modelos de negócios } \\
\text { CANVAS; } \\
\text { - Capacidade } \\
\text { desenvolvida } \\
\text { complementarmente à de } \\
\text { operação. }\end{array}$ & $\begin{array}{l}\text {-É a segunda capacidade } \\
\text { mais desenvolvida nas } \\
\text { startups, mas a mais } \\
\text { desenvolvida em algumas } \\
\text { firmas; } \\
\text { - A rede de relacionamentos } \\
\text { da startup é um dos fatores } \\
\text { mais importantes nos } \\
\text { primeiros anos da startup; } \\
\text { - As aceleradoras auxiliam as } \\
\text { startups a obter clientes e } \\
\text { investidores, promovem } \\
\text { workshopse aproximam } \\
\text { startups de outros } \\
\text { profissionais; } \\
\text { - O relacionamento com } \\
\text { universidades, fornecedores, } \\
\text { e aceleradoras minimizam os } \\
\text { riscos de ser um novo } \\
\text { entrante no mercado; } \\
\text { - Apenas uma startup não } \\
\text { possui apoio de incubadora e } \\
\text { aceleradora, por acreditar ser } \\
\text { desnecessário; } \\
\text { - A transação representa a } \\
\text { validação, pelo mercado, do } \\
\text { produto desenvolvido (que é } \\
\text { adaptado se não for bem } \\
\text { aceito). }\end{array}$ \\
\hline$T$ & \multicolumn{2}{|c|}{$\begin{array}{l}\text { As capacidades de operação e gestão são } \\
\text { desenvolvidas em um segundo momento } \\
\text { pelas startups. }\end{array}$} & \\
\hline
\end{tabular}

Fonte: Elaborada pelos autores.

\section{CONSIDERAÇÕES FINAIS}

Com o objetivo de caracterizar e analisar as capacidades de inovação das startups, identificou-se, primeiramente, que essas apresentam duas capacidades predominantes: a de desenvolvimento e a de transação. Já as firmas apresentam as quatro capacidades, mesmo que desenvolvidas em diferentes níveis e intensidades. Observou-se que o alinhamento entre a equipe que compõe a startup é considerado fundamental pelos integrantes da empresa, estando muito claro para os entrevistados que a startup deve preencher uma lacuna de mercado, compreender as necessidades desse e ser capaz de modificar o produto para obter esse alinhamento.

Por outro lado, analisa-se que as startups, inicialmente, desconsideram aspectos da gestão, pois essa 
passa a ser relevante apenas na medida em que os processos existentes se tornam mais complexos. Muitas delas não possuem um plano de negócios formal, mas um modelo de negócios CANVAS. A adoção deste tipo de modelo de negócios ocorre tendo em vista que a realidade de uma startup apresenta características dinâmicas, sendo comum que o bem ou o serviço desenvolvido sofra alterações, o que poderia significar reescrever o plano de negócios diversas vezes por mês, por exemplo. Mesmo as startups que já possuem seu bem/serviço definido consideram a elaboração de um plano de negócios como uma tarefa desnecessária, talvez pela possibilidade das dimensões do modelo de negócios sofrerem alterações. Ao se tornarem firmas, as startups reconhecem a importância do plano de negócios, pois ele fornece uma direção, uma perspectiva, para que a empresa se organize e, consequentemente, possa expandir. Naturalmente, a importância do plano de negócios para uma firma é relevante porque ela já tem seu modelo de negócios definido e consolidado, ao contrário de uma startup, cujo modelo de negócios ainda carece de definições.

Como observado, nenhuma das startups entrevistadas apresenta a capacidade operacional consolidada e, até que elas descubram como escalar seu negócio, essa capacidade está sujeita a mudanças. As empresas (firmas) destacam, ainda, que o crescimento da operação somente foi possível com a expansão da gestão na empresa. Essa interdependência pode ser claramente observada no caso da empresa $B$, que evidencia 0 alinhamento dessas duas capacidades como imprescindível para o seu negócio, e no caso da startup $\mathrm{D}$, que aponta ter percebido a necessidade de melhorar aspectos da gestão. Isto é, apenas na medida em que as startups se consolidam e crescem como organização é que essas capacidades - operação e gestão - passam a integrar as suas rotinas.

Aparentemente, startups que possuem o apoio de uma aceleradora possuem maior clareza no que tange ao seu negócio, que abrange não apenas a gestão, mas o entendimento do próprio diferencial competitivo da empresa frente aos concorrentes, 0 que permite que ela se posicione melhor no mercado e tenha maior clareza ao explicar o que é seu produto. A aceleradora, assim como os fundos de investimento, como visto neste estudo, contribui para o desenvolvimento e 0 fortalecimento das capacidades de gestão e transação, principalmente ao facilitar o acesso a investidores e pessoas que possuem conhecimentos do negócio.

Entende-se, desta forma, que o modelo das quatro capacidades de inovação desenvolvido por Zawislak et al. $(2012,2013,2014)$ auxilia startups a identificar suas fragilidades, embora careça de ajustes para ser adotado por esse formato de organização. É adequado por retratar quatro macro segmentos cruciais de um agente econômico que transaciona no mercado e por reunir, em quatro dimensões, as capacidades essenciais que uma empresa deve ter para ser capaz de transacionar com sucesso. Por outro lado, alguns dos critérios adotados para a análise dessas quatro capacidades não se aplicam à realidade dessas startups. Como foi observado, uma startup é demasiadamente enxuta para conceber departamentos específicos de marketing ou de P\&D ou, ainda, avaliar investimentos feitos em P\&D.

Para uma startup, eficiência e rapidez são fundamentais, o que implica, também, um modelo de capacidade condizente com essa realidade. Este modelo tende a permitir, então, às startups identificar quais das suas capacidades organizacionais estão menos desenvolvidas, evitando assim que incorram no erro de negligenciar capacidades cruciais para que se transformem em firmas de sucesso e sejam capazes de transacionar seus bens ou serviços. Acredita-se que a adaptação desses critérios e a adoção desse modelo seja um primeiro passo na tentativa de que startups passem, de fato, a contribuir com o desenvolvimento tecnológico em países em desenvolvimento. Deve-se atentar, ainda, para a natureza dos programas governamentais de apoio e incentivo, que devem ser planejados visando ao tipo de startup que se deseja fomentar, para que elas possam, de fato, contribuir com o desenvolvimento econômico do país por meio da criação valor.

Embora a natureza exploratória do estudo não permita generalizar os resultados, a partir das análises empreendidas emergem questões a serem aprofundadas em estudos futuros. Entre elas está a necessidade de compreender como se configuram essas diferentes capacidades em startups em um ambiente no qual 0 ecossistema de startups esteja consolidado, o que permitirá compreender, também, quais são os critérios que podem ser adotados para retratar cada uma das capacidades nas startups.

\section{REFERÊNCIAS}

AAKER, David K.; KUMAR, Vinay; DAY, George S. Pesquisa de Marketing. 2. ed. São Paulo: Atlas, 2007.

ANOKHIN, Sergey; WINCENT, Joakim. Start-up rates and innovation: a cross-country examination. Journal of International Business Studies, v. 43, p. 41-60, 2012. 
ARRUDA, Carlos et al. Causas da mortalidade de startups brasileiras: o que fazer para aumentar as chances de sobrevivência no mercado? Núcleo de Inovação e Empreendedorismo: Fundação Dom Cabral, 2014. Disponível em: <http://www.fdc.org.br/blogespacodialogo/Lists/Postagens/Post.aspx?ID=384>. Acesso em: 23 nov. 2014.

ASSOCIAÇÃO BRASILEIRA DE STARTUPS. Manual sobre conceitos, metodologias e investimentos em startups. Disponivel em: <http:// http://www.abstartups.com.br/>. Acesso em: 28 set. 2014.

BARDIN, Laurence. Análise de Conteúdo. Lisboa: Edições 70, 2006.

BLANK, Steve. The four steps to the epiphany. K\&S Ranch, 2013.

COCKBURN, lain M.; HENDERSON, Rebecca M.; STERN, Scott. Untangling the origins of competitive advantage. Strategic Management Journal, v. 21, n. 10-11, p. 1123-1145, 2000.

COHEN, Wesley M.; LEVIN, Richard C.; MOWERY, David C. Firm Size and R\&D Intensity: a Re-Examination. NBER Working Paper Series, n. 2205, apr. 1987.

DECAROLIS, Donna M.; DEEDS, David L. The impact of stocks and flows of organizational knowledge on firm performance: an empirical investigation of the biotechnology industry. Strategic Management Journal, v. 20, n. 10, p. 953-968, 1999.

DEEDS, David L.; DECAROLIS, Donna M; COOMBS, Joseph E. The impact of firm-specific capabilities on the amount of capital raised in an initial public offering: evidence from the biotechnology industry. Journal of Business Venturing, v. 12, n. 1, p. 31-46, 1997.

FINANCIADORA DE ESTUDOS E PROJETOS. Glossário: termos e conceitos. Disponível em: <http://www.finep.gov.br/biblioteca/glossario>. Acesso em: 28 set. 2014.

GEORGE, Gerard; ZAHRA, Shaker A.; WOOD, D Robley. The effects of business-university alliances on innovative output and financial performance: a study of publicly traded biotechnology companies. Journal of Business Venturing, v. 17, n. 6, p. 577-609, 2002.

GUAN, Jiancheng; MA, Nan. Innovative capability and export performance of Chinese firms. Technovation, v. 23, p. 737-747, 2003.

LEE, Choonwoo; LEE, Kyungmook; PENNINGS, Johannes M. Internal capabilities, external networks, and performance: a study on technology-based ventures. Strategic Management Journal, v. 22, n. 6-7, p. 615-640, 2001.

LERNER, Josh. The future of public efforts to boost entrepreneurship and venture capital. Small Business Economics, v. 35, n. 3, p. 255-264, 2010.

MACIEL, Cristiano O. Comportamento empreendedor e capacidades organizacionais: hierarquização e mensuração de seus efeitos no desempenho de empresas de pequeno porte. Revista Alcance, v. 16, n. 1, p. 026-044, 2009.

MALHOTRA, Naresh K. Pesquisa de Marketing: uma orientação aplicada. 3. ed. Porto Alegre: Bookman, 2001.

MASON, Colin; BROWN, Ross. Creating good public policy to support high-growth firms. Small Business Economics, v. 40, p. 211-225, 2013.

PE'ER, Aviad; KEIL, Thomas. Are all startups affected similarly by clusters? Agglomeration, competition, firm heterogeneity, and survival. Journal of Business Venturing, v. 28, p. 354-372, 2013.

RENKO, Maija; CARSRUD, Alan; BRÄNNBACK, Malin. The Effect of a Market Orientation, Entrepreneurial Orientation, and Technological Capability on Innovativeness: a study of young biotechnology ventures in the United States and in Scandinavia. Journal of Small Business Management, v. 47, n. 3, p. 331-369, 2009.

ROESCH, Sylvia M. A. Projetos de estágio e de pesquisa em Administração: guia para estágios, trabalhos de conclusão, dissertações e estudos de caso. 3. ed. São Paulo: Atlas, 2009.

ROTHAERMEL, Frank T.; DEEDS, David L. Alliance type, alliance experience and alliance management capability in high-technology ventures. Journal of Business Venturing, v. 21, p. 429-460, 2006.

SCHUMPETER, Joseph A. A Teoria do Desenvolvimento Econômico. 2. ed. São Paulo: Nova Cultural, 1985. (Coleção Os Economistas). 
SHAN, Weijan; WALKER, Gordon; KOGUT, Bruce. Interfirm cooperation and startup innovation in the biotechnology industry. Strategic Management Journal, v. 15, n. 5, p. 387-394, 1994.

SHANE, Scott. Why encouraging more people to become entrepreneurs is bad public policy. Small Business Economics, v. 33, n. 2, p. 141-149, 2009.

SHANE, Scott. The illusions of entrepreneurship: The costly myths that entrepreneurs, investors, and policy makers live by. New Haven, CT: Yale University Press, 2010.

SIGMUND, Stefan; SEMRAU, Thorsten; WEGNER, Douglas. Networking Ability and the Financial Performance of New Ventures: Moderating Effects of Venture Size, Institutional Environment, and their Interaction. Journal of Small Business Management, v. 53, n. 1, p. 266-283, 2015.

STINCHCOMBE, Arthur L. Social structure and organizations. In: MARCH, James G. (Org.). Handbook of Organizations. Chicago: IL: Rand McNally, 1965. p. 142-193.

TEECE, David J.; PISANO, Gary; SHUEN, Amy. Dynamic capabilities and strategic management. Strategic Management Journal, v. 18, n. 7, p. 509-533, 1997.

WENNEKERS, Sander et al. Nascent entrepreneurship and the level of economic development. Small Business Economics, v. 23, n. 3, p. 293-309, 2005.

ZAWISLAK, Paulo A. et al. Innovation capability: From Technology Development to Transaction Capability. Journal of Technology Management and Innovation, v. 7, n. 2, p. 14-27, 2012.

ZAWISLAK, Paulo A. et al. Influences of the Internal Capabilities of Firms on their Innovation Performance: a case study investigation in Brazil. International Journal of Managemeint, v. 30, n. 1, p. 329-348, 2013.

ZAWISLAK, Paulo A. et al. The different innovation capabilities of the firm: further remarks upon the Brazilian experience. Journal of Innovation Economics \& Management, n. 13, p. 129-150, 2014.

ZHENG, Yanfeng; LIU, Jing; GEORGE, Gerard. The dynamic impact of innovative capability and inter-firm network on firm valuation: A longitudinal study of biotechnology start-ups. Journal of Business Venturing, v. 25, n. 6 , p. 593-609, 2010.

i Originalmente publicado em 1912. 